\title{
Projetos de igualdade de direitos às pessoas LGBT: significados das/ os professoras/es sobre 0 seu protagonismo
}

\section{Projects of equality of rights to LGBT people: meanings of teachers on their protagonism}

\section{Proyectos de igualdad de derechos a las personas LGBT: significados de las/ los profesoras(es) sobre su protagonismo}

\author{
André Luiz Machado das Neves* \\ Universidade do Estado do Amazonas - UEA, Manaus, Amazonas, Brasil \\ I olete Ribeiro da Silva** \\ Universidade Federal do Amazonas - UFAM, Manaus, Amazonas, Brasil
}

\begin{abstract}
RESUMO
O presente artigo aborda os significados atribuídos por professoras e professores sobre o protagonismo em projetos de promoção à igualdade de direitos, voltados à LGBT na escola. Utilizou-se a abordagem qualitativa a partir da perspectiva histórico-cultural. Participaram 05 professores que atuavam na rede estadual de Manaus, Amazonas. Realizou-se entrevistas semiestruturadas, individuais. Para análise dos dados, foi utilizada a proposta de Núcleos de Significação. Verificou-se que os significados das/os participantes como: não obrigação, cobrado, forçado, imposição e aversão funcionam como mantenedores da não implicação com à promoção da igualdade de direitos com LGBT na escola. Porém, há professores que compreendem a importância desta atuação em projetos dessa natureza. Destaca-se que neste contexto, apenas um professor verbalizou essa relevância em seu discurso. Por outro lado, foi verificado uma professora que "por questões religiosas" não se vincularia a projetos que abordassem o tema gênero e sexualidade e outro professor que alegou que se tivesse tempo ou fosse dispensado da carga horária participaria. É invisível nas narrativas a transversalidade desses temas como um assunto que pode ser abordado em sala de aula. Se fosse transversal ao menos na sala, seria uma possibilidade de protagonismo em projetos/ações de igualdade de direitos à LGBT na escola.
\end{abstract}

Palavras-chave: educação, gênero, direitos, LGBT, professores.

\section{ABSTRACT}

This article addresses the meanings attributed by teachers as their protagonism in projects to promote equal rights to LGBT students at the school. A qualitative approach from the historical-cultural perspective was performed. Five teachers who worked at state schools in Manaus, Amazonas State, Brazil, participated in the study. Semi-structured individual interviews 
were conducted. It was used the Nuclei of Significance proposal. It was verified that the meanings of the participants, such as no obligation, asked, forced, imposed, and aversion maintain the non-implication with the promotion of equal rights with LGBT at school. However, there are teachers who understand the importance of this participation in these types of projects. It is noteworthy that in this context, only one teacher talked about this relevance. On the other hand, another teacher, "due to religious reasons", said that she would not be involved in projects related to gender and sexuality subjects, and another one stated that if he had the time or if he was exempted from his workload, he would participate in the projects. In the narratives, there is no transversality of these subjects as a topic that can be approached in the classroom. If they were transversal subjects at least in the classroom, there would be a possibility of protagonism in projects/measures of equality of rights to the LGBT at the school.

Keywords: education, gender, rights, LGBT, teacher.

\section{RESUMEN}

El presente artículo aborda los significados atribuidos por profesoras(es) sobre su protagonismo en proyectos para promover la igualdad de derechos relacionados con la LGBT en la escuela. Se utilizó el enfoque cualitativo a partir de la perspectiva histórico-cultural. Cinco profesores de la red estadual de enseñanza de Manaus (Estado de Amazonas, Brasil) participaron del estudio. Se realizaron entrevistas semi-estructuradas individuales. Para el análisis de los datos, se utilizó la propuesta de Núcleos de Significación. Se verificó que los significados de las/los participantes como: no obligación, cobrado, forzado, imposición y aversión funcionan como mantenedores de la no implicación con la promoción de la igualdad de derechos con LGBT en la escuela, pero hay profesores que comprenden la importancia de la participación en proyectos de esa naturaleza. Es importante destacar que, en este contexto, sólo un profesor mencionó esa relevancia en su discurso. Por otro lado, una profesora que "por cuestiones religiosas" dijo que no se vincularía a proyectos que abordan el tema género y sexualidad, y otro profesor que alegó que, si tuviera tiempo o fuera dispensado de su carga horaria, participaría en el proyecto. No se ve en las narrativas la transversalidad de estos temas como un asunto que puede ser abordado en el aula. Si el tema fuera transversal por lo menos en el aula, sería una posibilidad de protagonismo en proyectos/acciones de igualdad de derechos a la LGBT en la escuela.

Palabras clave: educación, género, derechos, LGBT, profesores.

\section{Introdução}

Com a aprovação do Plano Nacional de Educação (PNE) em 2014, que determina que as unidades federativas e municípios brasileiros deveriam formular seus planos de educação, ou adaptar os já aprovados em lei, conforme o texto nacional no prazo de um ano, iniciou-se uma "cruzada" 1 com o intenso debate em torno da inclusão ou não de temas referentes a gênero e sexualidade nos planos estaduais, distritais e municipais de educação já elaborados.

Esta cruzada é articulada por religiosos conservadores, que justificam a rejeição das discussões de gênero e sexualidade na educação, sob o 
argumento - difamatório - de que esses debates em sala de aula visam a "revolução socialista" e para que isso aconteça, se faz necessário, conforme a "doutrina marxista" a "destruição da família" e a perversão dos sexos biológicos (Ferreira et al., 2015, p. 04; 13). $\mathrm{E}$, portanto, esse seria o papel do que pejorativamente nominaram de "cultura da morte" ou "ideologia de gênero". Esta última, categoria política cunhada a partir dos anos 2000, por movimentos reacionários e conservadores religiosos diante da retórica oriunda no âmbito da Igreja Católica ${ }^{2}$ (e posteriormente compartilhada por outras igrejas). "Trata-se de uma reação, após algumas décadas de avanços na igualdade de gênero e nos direitos sexuais e reprodutivos, que se estende por uma grande quantidade de países nas Américas e na Europa" (Cornejo-Valle \& Pichardo, 2017; Facchini \& Parreiras, 2017). Lançando mão desta categoria política, é que esse movimento, autodenominado de movimento contra a "Ideologia de Gênero", ganha visibilidade. Inicia-se, por sua vez, um investimento desse movimento, compreendido pelo autor e autora deste artigo como a produção de um Pânico Moral. A saber: “Uma condição, um episódio, uma pessoa ou um grupo de pessoas passa a ser definido como um perigo para valores e interesses societários; sua natureza é apresentada de uma forma estilizada e estereotipada pela mídia de massa; as barricadas morais são preenchidas por editores, bispos, políticos e outras pessoas de Direita; especialistas socialmente aceitos pronunciam seus diagnósticos e soluções; recorre-se a formas de enfrentamento ou desenvolvem-nas" (Cohen, 1972, p. 9).

Nesse sentido, embora em 2014 esse movimento tenha ganhado visibilidade no Brasil por meio do dispositivo do Pânico Moral, supõem-se que essa visibilidade, soma-se ao momento de crise política vivenciada pelo país que culmina com o impeachment em 2016 da Presidenta Dilma Rousseff. Veja-se:

Dias depois de o vice-presidente do Brasil assumir interinamente a Presidência da República e anunciar a organização do seu novo ministério, uma adolescente carioca foi violentada sexualmente por vários homens. Na mesma semana, o novo Ministro da Educação reuniu-se com o ator Alexandre Frota e representantes dos Revoltados On Line e Escola sem Partido, movimentos defensores de um programa de educação pública sem "doutrinação política" e "ideologia de gênero". Em 2014, esse ator foi acusado de apologia ao crime de estupro por narrar jocosamente à violação de uma mulher em um programa humorístico da televisão brasileira.

$O$ presidente interino [Michel Temer] - que nomeou o ministro da Educação que recebeu o ator que "sapecou a mãe de santo"

- repudiou veementemente o estupro coletivo e, rememorando-se como 0 criador da primeira delegacia 
brasileira de proteção à mulher, comprometeu-se a criar um departamento na Polícia Federal para combater os crimes de estupro no país, dias depois de extinguir o Ministério das Mulheres, da Igualdade Racial, da Juventude e dos Direitos Humanos (Cunha, 2016, p. 1-2).

Os fatos da pesquisa etnográfica acima, da antropóloga Flávia Melo da Cunha elucidam as alianças do governo federal com alguns dos grupos que se encontram junto aos movimentos feministas, acadêmicos, movimento LGBT nas disputas e tensões, entre a proibição ou não da discussão de gênero e sexualidade na educação.

Embora tenham-se essas premissas das tensões e disputas em torno da discussão ou não de gênero e sexualidade na escola em tempos de "ideologia de gênero" no Brasil, destaca-se que em 2011 com o embargo do Projeto Escola sem Homofobia - que possuía um kit antihomofobia, composto de um caderno, uma série de seis boletins, três audiovisuais com seus respectivos guias, um cartaz e uma carta de apresentação para gestoras e educadoras - já ocorria pressão de parlamentares fundamentalistas religiosos, que dificultava a implementação de projetos que discutissem a igualdade de direitos para LGBT na escola, que obstaculizavam a realização de debates e evitavam que essas discussões saíssem do papel (Melo, Freitas, Pedrosa, \& Brito, 2012). Destaca-se que foi um momento em que o "kit anti-homofobia" foi desfavoravelmente chamando-o de "kit gay", discursos fervorosos afirmavam que esse material estimularia os alunos e alunas "se tornassem homossexuais". É nesse contexto que esta pesquisa realizada em 2013 se localiza. Momento em que não era tão organizada as relações entre religiões e esfera pública em contextos de avanço de conservadorismos para difamar as políticas de gênero e sexualidade no Brasil.

Partindo desse viés, este artigo visa abordar os significados atribuídos por professoras/es sobre 0 protagonismo ${ }^{3} \mathrm{em}$ projetos ${ }^{4}$ de promoção à igualdade de direitos voltados à LGBT na escola, considerando que as/os professoras/es são pessoas necessárias e fundamentais para implantação, execução e construção de políticas públicas voltadas à igualdade de direitos no ambiente escolar.

Nesse âmbito, a promoção de igualdade de direitos é um dos princípios fundamentais tanto para a Psicologia quanto para a Educação, por ser algo inalienável a qualquer ser humano. No entanto, muitas vezes, são usurpados em decorrência das relações de poder em consequência de uma disputa política socialmente construída, realidade que se caracteriza entre os grupos que tentam dominar o outro, no qual o grupo dominante acaba negando muitas vezes e inviabilizando lutas e disputas, criando assim, ideologias negativas em torno de grupos considerados inferiores e não dominantes, como é o caso das pessoas LGBT. As consequências da 
desigualdade e exclusão, atualmente vivenciadas por indivíduos pertencentes a grupos sociais oprimidos, acarretam a demanda de dificuldades para afirmação de suas identidades em espaços públicos (Prado, Torres, Machado, \& Costa, 2009).

Silva e Maciel (2006) consideram que o espaço escolar se produziu num construto cultural que expressa e reflete significados, ao mesmo tempo em que impõe leis que buscam disciplinar e regular as condutas. Por uma educação igualitária e uma escola para todas e todos, que respeite a singularidade das pessoas, os movimentos sociais, pautados nos direitos humanos e princípios de cidadania, investem em discussões para uma educação igualitária voltada à diversidade, entre eles podem-se elencar os movimentos sociais das pessoas com deficiência, os de raça, cor e orientação sexual.

Visou-se, nessa perspectiva, produzir um conhecimento mais contextualizado, significativo e interdisciplinar, permeando o campo de estudo dos direitos humanos, da psicologia e da educação. A pesquisa teve o intuito de contribuir com novos aspectos constituintes da transformação social em interlocução com o conhecimento da psicologia e o contexto escolar no que se refere à promoção de direitos humanos e inovação na educação, pois a psicologia deve encontrar um caminho que traga contribuições que produzam a transformação social que envolva diversas instituições como a família, a escola e a comunidade (Silva \& Maciel, 2006).

O artigo encontra-se pautado na perspectiva crítica da psicologia histórico-cultural. Essa perspectiva destaca a importância da cultura, pois para Vigotski (2001), o grupo cultural fornece ao indivíduo um ambiente estruturado, onde os elementos são carregados de significado cultural. Para tanto, adotou-se a categoria de significados, desta perspectiva, na qual se entende que as palavras fornecem a mediação simbólica entre o indivíduo e o mundo, ou seja, é no significado da palavra que a fala e o pensamento se unem em pensamento verbal socialmente compartilhado.

\section{Método}

\subsection{Tipo de estudo}

Trata-se de um estudo amparado na abordagem qualitativa de pesquisa, a partir da perspectiva teórica da psicologia históricocultural. Esse enfoque concebe o fenômeno psicológico partindo de sua relação dialética com o mundo social, histórico e material. Compreende, dessa maneira, o/a homem/mulher ativo/a e em processo constante de desenvolvimento, entranhado nas relações sociais como produtor/a construtor/a, transformador/a e transformado/a pelo meio social (Bock, Gonçalves, \& Furtado, 2002). 


\subsection{Participantes}

Participaram do estudo 05 professoras/es que atuavam em uma escola da rede estadual de ensino na cidade de Manaus, Amazonas. Entende-se que cada participante se apropria de forma subjetiva e particular do social, trazendo consigo não apenas a sua voz, mas outras vozes. Seus discursos expressam múltiplas vozes e sentidos construídos no contexto social (Rosa \& Andriani, 2008). Não se pretende generalizar os dados aqui discutidos, mas entende-se que as reflexões construídas com esse pequeno número de professores e algumas unidades discursivas de análise podem contribuir para reflexões em outros âmbitos escolares.

Das(os) participantes, 03 se autodefiniram do sexo feminino e 02 do sexo masculino. No que tange a faixa-etária, 02 possuíam menos que 30 anos, e 03 encontravam-se na faixa de idade entre 30 a 50 anos. Desses, três participantes possuíam graduação na área das Ciências Humanas, um deles na área das Ciências Sociais Aplicadas e uma na área das Ciências Biológicas. No tocante à formação pós-graduada, apenas dois possuíam um curso de Pós-Graduação Lato Sensu e nenhum(a) professor(a) com formação Stricto Sensu.

O tempo de atuação das(os) participantes na Rede Estadual de Ensino é bem heterogêneo. Destaca-se que duas professoras atuavam na rede estadual de ensino entre um a quatro anos e três professores/as entre três entre cinco a dez anos. No que se refere ao tempo de atuação na escola pesquisada, duas participantes estavam trabalhando a menos de cinco anos e três possuíam um tempo de cinco a dez anos na escola. Já na definição de sua religiosidade, quatro professoras/es se autodeclararam católicos e uma evangélica.

O contexto em que as/os participantes atuavam como professoras/es se caracterizou em uma escola localizada no bairro Cidade Nova I na Zona Norte da capital. Essa escola atua apenas no Ensino Médio nos três turnos. Na época da pesquisa, a instituição contava com sete projetos voltados ao ensino-aprendizagem. Dente esses projetos, um abordava a preservação da identidade ético-cor-racial brasileira de abordagem interdisciplinar. Esse mesmo projeto a partir de 2012, iniciou intervenções com à temática da diversidade sexual e gênero e sobre religiões de matriz africana, a partir de obras literárias brasileiras.

\subsection{Instrumento}

Foram realizadas entrevistas semiestruturadas, individuais. Segundo Aguiar e Ozella (2006), esse tipo de entrevista a partir da psicologia histórico-cultural, é um dos instrumentos mais favoráveis permitindo o acesso aos processos psíquicos para compreensão dos sentidos e significados das(os) participantes. Foi atribuído aos docentes a letra 
"P" que indica "professora" ou "professor" acompanhado de um número natural dado conforme as realizações das entrevistas e a letra $M$ ou $F$ indicando masculino ou feminino, conforme se autodefiniram.

\subsection{Procedimentos}

A pesquisa obteve a aprovação do Comitê de Ética em Pesquisa da Universidade Federal do Amazonas, sob o número de protocolo 371.535. Utilizou-se durante a pesquisa o Termo de Consentimento Livre e Esclarecido (TCLE) assinado pelos sujeitos pesquisados, além das autorizações institucionais pertinentes a cada campo de pesquisa. Foi preservado o anonimato da instituição e dos participantes.

As(os) participantes foram entrevistadas/os individualmente e 0 procedimento utilizado para a seleção das entrevistadas(os) foi a informante chave. Destaca-se que muitos professores trabalham em outras escolas e isso fazia com que eles não ficassem muito tempo na instituição. Todos foram apresentados e agendados pela coordenadora de projetos da escola.

O primeiro contato com coordenadora de projetos foi realizado por meio da diretora. Após isso, explicou-se o objetivo do trabalho e a importância de que a entrevista fosse gravada. Efetuado o agendamento do encontro, este ocorreu em local na biblioteca da escola. As entrevistas foram então realizadas e gravadas, e sua transcrição foi feita na íntegra. Porém, neste artigo, foram trabalhadas apenas algumas unidades de análise.

\subsection{Análise dos dados}

Os dados foram analisados baseados na proposta TeóricoMetodológica de Vigotski apontado por Aguiar e Ozella (2006) da constituição dos Núcleos de Significação como instrumento para apreensão dos sentidos. Seguiu-se os seguintes procedimentos: Préindicadores; Indicadores e Construção e Análise dos Núcleos de Significação. Nesta perspectiva de análise, propõe-se que essa nomeação dos núcleos pode ser retirada da própria fala do sujeito em uma ou mais expressões que favoreçam a articulação realizada na elaboração dos núcleos e o protagonismo do sujeito inserido nos objetivos da pesquisa (Aguiar \& Ozella, 2006). 


\section{Resultados e Discussão}

\section{1 “Que não seja cobrado, que não seja obrigado"}

Esse núcleo de significado, apresenta discursos de duas professoras, que consideram que não se deve tratar do tema igualdade de direitos, durante as aulas como algo obrigatório. Elas sugerem que essa educação é uma tarefa coletiva, que envolve uma vinculação afetiva não devendo ser permeada pela obrigação.

“(...) assim algo que não seja cobrado, que não seja algo obrigado, mas algo mesmo que nos leve enquanto professores a trabalhar com os alunos, para alcançarmos nossos objetivos". P1F

“Olha, eu acho que tudo que é forçado não é legal, entende? Então, o plano [de ensino] mesmo se a gente for impor as coisas para eles, acabam tendo aversão... A educação tem que ser pelo amor, entende? Pelo amor eles conseguem vir, acabam vindo e acabam fazendo uma parceria. Mas se você impor, impor alguma coisa (...)". P3F

O discurso de P1F e P3F possibilita a análise de que o processo de transformação do cotidiano e a adaptação constante aos novos processos de significação na sociedade e, consequentemente, na escola, ainda não se apresentam na linguagem das professoras. P1F e P3F apresentam narrativas que revelam que ambas não se percebem como pessoas ativas nessa promoção de igualdade de direitos, utilizando a questão do "obrigado" e "forçado" como uma forma de não se implicar. É fundamental que essas participantes sintam-se ativas nesses projetos, por entender que elas são formadoras de opinião e inspiração em contato com alunas(os) todos os dias em sala de aula.

De acordo com Neves e Silva (2017), uma educação igualitária que inclua a todas(os) e promova saúde psicológica, depende da presença de professoras(es) ativas/os, no sentido Vigotskiano, pois a/o professora/o pode acrescentar positivamente no desenvolvimento das(os) alunas(os), principalmente, no que tange aos aspectos psicossociais e na mediação em sala de aula. Tudo isso por que são elas(es), professoras(es) que promovem troca de percepções, opiniões, vida e decisões de qualquer esfera no âmbito escolar. Verifica-se, dessa maneira, que um (a) professor (a) que se percebe como pessoa ativa nessa promoção de igualdade de direitos, pode promover relações menos conflituosas ou geradoras de sofrimento a todos os tipos de diversidade em sala de aula (Neves, 2013). Assim, as relações poderiam fluir de maneira igualitária, respeitosa e, 
principalmente, sem oprimir o desenvolvimento e os processos psicossociais de cada um/a.

Segundo Junqueira (2009), professoras/es, ao terem contato com projetos voltados a igualdade de direitos em gênero e sexualidade, podem tornar-se protagonistas no fazer uma escola na e para a diversidade, podem contribuir para a transformação desejada, promovendo garantia de direitos e uma educação com equidade, contribuindo para cidadania, o enfrentamento das situações de homofobia na escola e na formação profissional das(os) alunas(os). Nesse sentido, a escola estará aberta a todas(os), possibilitando oportunidade de educação e perspectivas futuras para a profissionalização das(os) alunas(os).

Analisou-se, por meio do discurso das participantes P1F e P3F, duas dimensões existentes nos significados de protagonismo em projetos de igualdade de direitos: a imposição e execução paulatina.

No que tange à dimensão imposição, elas compreendem que esta ação não levará a contribuir para a igualdade desejada e, sim para o fomento de aversão entre os atores da comunidade escolar. Desse modo, do ponto de vista das mesmas, a imposição se caracteriza como um significado negativo para o protagonismo.

De acordo com Lucci (2006), o/a professor/a, todavia, protagonista principal no processo educacional escolar, por ser o responsável pela construção de conhecimentos em sala de aula e de experiências de vida, tem como ferramenta a linguagem, que funciona como mediação simbólica favorecendo a comunicação, planejamento, autorregulação em sala de aula. É pela sua função comunicativa que as pessoas se apropriam do mundo externo, pois é por meio da comunicação estabelecida na interação que ocorrem negociações, reinterpretações das informações, dos conceitos e significados do convívio social.

Ao falar sobre o protagonismo de professoras/es, Avila, Toneli e Andaló (2013) afirmam que as posturas e a construção da prática das/os professoras/os em sala de aula, em sua maioria se limitam e se constroem no domínio dos conteúdos das matérias e na manutenção do controle da turma. As(os) autoras(es) ainda ressaltam que as(os) professoras(es) adotam, muitas vezes, quando se trata de gênero e sexualidade, vozes baseadas nas experiências de suas vidas e, desse modo, constituem uma forma particular no seu saber-fazer delimitada pela lógica religiosa ou biologicista. Nesse contexto, acaba não acontecendo o protagonismo de fato, por se desconsiderar um olhar mais amplo e transversal em sala de aula, ao se abordar a sexualidade e gênero enquanto temática de educação interdisciplinar que envolve aspectos políticos e culturais.

Os discursos de P1F e P3F fazem compreender que trabalhar com igualdade de direitos pode ser benéfico. Porém, reivindicam de forma enfática, a não obrigatoriedade do diálogo de igualdade de diretos 
para a população LGBT. Esse discurso pode demonstrar uma rejeição em trabalhar com o tema da sexualidade, por entender que levar para sala de aula seria uma imposição e isso acarretaria em "aversão". De acordo com Costa (2013), a igualdade de direitos, independente do desejo sexual de cada pessoa, deve ser entendida como parte do ser humano, como um processo inalienável. Falar de diversidade sexual, por exemplo, em sala de aula, é tentar compreender e discutir a promoção do respeito à dignidade humana. A não obrigatoriedade no discurso, se caracteriza como uma forma de não querer ter acesso à discussão.

De outro modo, quando P1F e P3F, evocam que a inserção de temáticas em sala de aula sobre igualdade de direitos frente à diversidade sexual pode ocasionar promoção de igualdade social e de direitos, mas que seja aos poucos, possibilitando a intepretação que deva ficar no "armário", identifica-se, um antagonismo nos discursos das participantes. Esses relatos, por sua vez, fogem à ideia de direito como algo inalienável ao sujeito. Espera-se que a(o) professora(or), enquanto agente público e independentemente de ser pró ou contra, articular-se para que a garantia do direito e individualidade de cada aluno sejam respeitados.

As professoras participantes da pesquisa, referem-se a uma característica da construção possibilitada pelos projetos de igualdade de direitos, apontando que esse processo é paulatino. Isto porque é necessário aos poucos envolver as pessoas em reflexões que façam frente aos estereótipos que foram construídos ao longo do tempo. Conforme P1F e P3F é preciso envolver as pessoas e fazer com que possam aderir a esses projetos, compartilhar da ideia de que ele é importante.

A necessidade de ser paulatino caracteriza-se pelo fato de que projetos dessa natureza são mediados pela construção de conceitos, concepções e demonstração de novas posturas frente ao processo histórico-cultural de cada pessoa. Concordando com González-Rey (2002) a subjetividade é um complexo de diversas significações e de sentidos subjetivos na vida da cultura humana e também do indivíduo.

Diante dessas questões, considera-se mais importante do que ser paulatino, que os professores sejam protagonistas frente a esses projetos, que sejam contínuos e não apenas focais, limitando-se apenas a uma intervenção. Em outras palavras, considera-se que pode até ser paulatino, mas se não houver continuidade ao longo do tempo ou se não houver nenhuma ação em sala de aula, não vai ocasionar os efeitos desejados ou nenhum efeito, especialmente se considerarmos o aspecto de que muitas pessoas entram e saem da escola o tempo inteiro.

Como se percebe, esses projetos na escola e a formação para a diversidade sempre serão necessários. A equipe vai se qualificando e 
amadurecendo por meio da interação com esses projetos à medida que as ações são executadas.

Ao analisar esses posicionamentos, o obrigatório parecer tem um lugar de velar uma desculpa para encobrir o preconceito. Ressalta-se que durante a discussão da implantação do projeto "Escola sem homofobia", também foi comum encontrar discursos que afirmavam que agora as(os) professoras(es) seriam obrigadas(os) a falar sobre homossexualidade. A partir disso, compreende-se como uma resistência, e não como uma flexibilidade, usando o caráter de democracia para dizer isso não, eu não quero, eu não faço.

Atualmente, movimentos como o da "Escola sem Partido" e de "contra a ideologia de gênero", contrários a discussão de gênero e sexualidade na escola, têm buscado por via da judicialização e difamação, a efetivação e construção de projetos de Leis e Leis em vários Estados e regiões do Brasil, com vistas a proibição dessas discussões em sala de aula (Amorim \& Salej, 2016). De acordo com Neves e Silva (2017), tais articulações legitimam a não obrigatoriedade de professores na promoção de igualdade de direitos para as pessoas LGBT em sala de aula, assim como negligenciam o enfrentamento à cultura do estupro, abuso sexual, violência contra a mulher e todas as desigualdades oriundas das hierarquias sexuais e de gênero.

\section{2 “Os projetos podem até vir para facilitar, para ajudar, mas se não houver uma participação ativa dos professores, alunos e dos pais..."}

Este núcleo de significado do protagonismo do(a) professor(a) revela a escola como um espaço de promoção de igualdade para estudantes LGBT, mas que depende de trabalho em conjunto, para além dos muros da escola, isto é, precisa envolver o contexto social e instituições nas quais as(os) alunas(os) estão inseridas/os.

“Eu acredito... Os projetos podem até vir para facilitar, para ajudar, mas se não houver uma participação ativa dos professores, alunos e dos pais... Pois, muitos pais acabam influenciando no preconceito $e$, isso os projetos viriam fazer mais números para gastar mais verbas e tudo. Mas, acredito que sim, se tiver uma conscientização dos alunos e dos pais dos alunos acredito que os projetos vão surtir efeito contra a discriminação na escola". P6M

Verifica-se que o professor P6M compreende que o preconceito é o reflexo de contextos fora do âmbito da escola, citando, por exemplo, oriundo dos pais. P6M, aponta que sua participação em projetos de igualdade de direitos pode até facilitar e ajudar. Porém, ele afirma 
acreditar que este processo de educação é coletivo, pois a escola não está isolada da sociedade. De acordo com Madureira e Branco (2015), os preconceitos acerca da sexualidade expressos na escola foram construídos dentro e fora dela. Esclarecer a sexualidade a partir de suas múltiplas faces se faz necessário, porque é preciso lembrar que muitos indivíduos estão inseridos num contexto sóciohistórico e também são produtos, em sua maioria, de uma educação sexual repressora, que não promove o desenvolvimento das habilidades necessárias a uma postura receptiva frente aos temas da sexualidade humana.

O direito à liberdade sexual é um direito inalienável e não se relaciona com uma escolha do(a) professor(a). Defende-se a ideia de que uma vez na qualidade de agente público, o(a) professor(a) tem que cumprir a lei, tendo em vista, inclusive, que cidadãos são assegurados pela lei máxima que é a Constituição. Mas, não se deixa de reconhecer a subjetividade do(a) professor(a) advinda dos aspectos sócio-históricos da construção e da processualidade do sujeito no que se refere aos aspectos de "verdades do sexo" que foram construídos por meio de uma lógica compulsória da heteronormatividade (Foucault, 1988; Butler, 2003).

Destaca-se, que é importante que os projetos de igualdade pensando a diversidade, sejam construídos em conjunto com as(os) professoras(es) para que estas/es sejam protagônicas/os e possam reconhecer/compartilhar a pertinência da implantação destes projetos. Assim, entende-se que essa estratégia de fazer junto, de co-construir pode favorecer a construção de concepções que fortaleçam a compreensão de que não é uma questão de privilégio de um grupo, mas de promoção de igualdade de direito pensando a diferença.

O avanço realizado por movimentos sociais e no campo da produção de conhecimento pautado para a promoção de direitos humanos tem conseguido produzir alguns resultados. Contudo, no ocidente, os sentidos subjetivos construídos, pela interferência da filosofia judaicocristã, ainda organizam atribuições de significados negativos que mediam os relacionamentos entre sujeitos, conforme vai se apresentando nos discursos abaixo.

Contudo, considerando o discurso inicial de P6M, que o protagonismo para promoção da igualdade de direitos é um trabalho coletivo, há casos em que a opinião religiosa sobrepõe a atuação da professora no contexto estudado, conforme pode ser observado no discurso a seguir:

“Não. Pela minha opinião mesmo, por questões religiosas. Não, assim, no caso da minha opinião, certas coisas que eu não concorde, mas não significa que eu ataque ou que eu procure colocar minha opinião como tem que ser a certa, a correta 
independente da minha condição de professora, eu não faço isso. Do meu lado, se fosse só eu seria positivo, porém talvez pelo lado de vocês na sua visão seria negativo, porque não iria tá participando de projetos ou incentivando a eles participarem". P5F

Acerca das motivações do protagonismo em projetos de igualdade de direitos para estudantes LBGT, o discurso da professora participante revela que elas não existem, pois prepondera o aspecto religioso, que parte de sua subjetividade para afirmar que não estaria participando e também não incentivaria os alunos a participarem. De outro modo, P5F afirma que busca uma opinião "neutra" tanto enquanto professora, quanto como sujeito, ao dizer que não coloca a opinião dela como a certa.

De acordo com Neves, Sadala, Silva, Teixeira, Ferreira e Silva (2015), a atuação de professoras(es) balizada pela filosofia judaico-cristã se faz presente no ambiente escolar. Muitas vezes, suas ações frente a discussões de temas sobre gênero e sexualidade, ancoram-se em opiniões pessoais transversalizadas pelo paradigma religioso cristão.

O antagonismo é algo presente na forma de significar o protagonismo. A neutralidade afirmada por P5F é inexistente, permitindo que os valores religiosos possam nortear o seu saberfazer. O discurso não protagônico nas questões de igualdade de direitos para LGBT na escola, ainda se evidencia pela ausência de tempo. A seguir, o registro de um discurso que confirma esta premissa:

"Olha se eu tivesse tempo ou dispensado pela escola, como eu trabalho em três horários, manhã, tarde e a noite, a escola liberando e servindo de base para poder melhorar o comportamento em relação a esse assunto, sim. [Sobre a motivação] O tempo! Teria que ter uma disponibilidade tempo. [Falando do resultado do projeto] Que se a gente falar que sim, e só se a gente aprender. Levar um grupo de professores para aprender sobre isso. Participar dessa formação e tal. E trazer para escola se não afetar diretamente os alunos. Acho que não influi em nada não. Então acredito que se eu falar atingiria ou não é meio complicado de se expressar isso. É um pouco complicado. Mas, seria um passo a mais para poder acabar com discriminação, 'discriminalizar' dentro escola. Discriminação [Quando você fala em atingir os alunos. Seria como?] Seria mostrando a disciplina, como eu sou formado em história, eu utilizaria o tema de forma histórica, perseguição das pessoas que tinham sexualidade diferente optado por uma opção sexual diferente poderia encaixar nisso ai, né?" P4M. 
O discurso acima permite vislumbrar um professor com uma tendência tecnicista de educação. Atribui às condições de trabalho como responsável para não estar motivado em ser protagonista, segundo ele, essa inviabilização se dá em decorrência de lecionar nos três turnos. P6M ainda considera complexo se perceber enquanto agente de transformação social, mas considera que a formação para a diversidade seria um passo para a transformação social.

Os discursos corroboram com as premissas de Silva (2013), que defendem a desconstrução do preconceito contra grupos marginalizados. A exclusão social ainda se refere claramente diante das relações de gênero que inviabilizam a igualdade sociopolítica e humana. A autora (p. 20-21), nesta perspectiva, resguarda-se da ideia de que "o contexto social da Educação é uma das vias de acesso ao conhecimento crítico da realidade sociocultural que fazemos parte".

\section{Considerações Transitórias}

O presente estudo abordou os significados atribuídos por professoras(es) ao protagonismo em projetos de promoção à igualdade de direitos voltados à LGBT na escola. Por meio dos discursos das(os) professoras(as), foi possível verificar que os sentidos que alicerçam a atribuição dos significados das(os) participantes como: não obrigação, cobrado, forçado, imposição e aversão funcionam como mantenedores da não implicação com à promoção da igualdade de direitos com LGBT na escola.

Contudo, apontamos outros sentidos que compõem os significados das(os) professoras/es como "a educação tem que ser por amor" e "por amor eles conseguem vir", e que eles podem ser frestas para construção e fortalecimento de projetos que visem à igualdade de direitos para LGBT na escola.

$\mathrm{Na}$ análise dos dados, constatou-se também que existe sim professor que compreende a importância dessa atuação em projetos dessa natureza, porém ele sinaliza que essa atuação é para além dos muros das escolas e, portanto, necessita da coletividade, por exemplo, a família, para "surtir efeito contra a discriminação na escola". Contudo, destaca-se que foi apenas um professor que trouxe esse discurso durante as entrevistas. Por outro lado, foi verificado uma professora que "por questões religiosas" não se vincularia a projetos que abordassem o tema gênero e sexualidade e outro professor que alegou que se tivesse tempo ou fosse dispensado da carga horária participaria.

Desvela-se que é invisível nas narrativas a transversalidade desses temas como um assunto que pode ser abordado em sala de aula. Se fosse transversal ao menos na sala, seria uma possibilidade de 
protagonismo em projetos/ações de igualdade de direitos à LGBT na escola.

Aponta-se a possibilidade, no ambiente da escola, que o professor permita que os saberes se expressem, considerando que as pessoas são produtoras do seu destino e que as diferentes formas de viver têm que ser entendida de maneira respeitosa na perspectiva dos direitos humanos.

O que faz diferença na educação para a diversidade é o método que fará a mediação. Deixando claro que não é obrigatório que o/a professor/a pense de uma forma e o/a aluno/a pense de outra, mas é fundamental que o método de permitir a liberdade dos pensamentos, dos desejos, a tolerância à pluralidade que acompanha o sujeito humano do início ao fim da vida. Por isso, consideramos relevante que esta função do diálogo e do respeito à pluralidade em todas as suas interfaces seja respeitada.

A Psicologia pode comprometer-se com ações que também aumentem a compreensão e a aceitação da diversidade (raças, cultura, grupos econômicos, etc.) no âmbito escolar, podendo oportunizar nas formações de professores - tanto na formação inicial e/ou continuada - perspectivas mais implicadas com a realidade e com os processos coletivos que demandam cada vez mais olhares pela via dialógica sobre a unidade na universalidade num caráter relacional, como é o caso da diversidade sexual e de gênero. E, desse modo, a prática da psicologia educacional e escolar esteja comprometida com o acesso e permanência à educação para todas as pessoas.

Espera-se contribuir para a reflexão do professor, enquanto agente participativo na transformação social, que eles sejam aliados para execução de projetos de políticas públicas voltadas à diversidade sexual e de gênero, e as(os) Psicólogas(os) elos para promoção de práticas educativas e promotoras dos direitos humanos das identidades LGBT, que não são dominantes e acabam sendo silenciadas pelas disputas nas relações de poder.

Destaca-se, nesse sentido, graves problemas frente ao movimento conservador que tenta se reinstalar no Brasil nos últimos anos, tais como: "Escola sem Partido" e movimento "contra a Ideologia de Gênero". Pois eles legitimam discursos disfarçados de democracia como a não obrigação, que não seja cobrado, que não seja forçado, a imposição e a aversão para o não favorecimento da construção de uma escola democrática e o fomento de uma educação para todas e todos.

De maneira geral, o que se verificou nas narrativas analisadas, é que antes de Leis e projetos de Leis ganharem visibilidade, já haviam dispositivos (tempo, religião, educação conteudista) que inviabilizavam a discussão de gênero e sexualidade, porém não oficializado comparado ao que se tem presenciado entre Leis, projeto 
de Leis, produção de livros e vídeos que atacam e difamam as políticas de gênero e sexualidade na educação. Sendo assim, essa temática continua velada e sempre foi um grande desafio para os educadores em suas práticas docentes. E em tempos de "ideologia de gênero" essas práticas tendem a se fortalecer.

\section{Referências}

Aguiar, W. M. J., \& Ozella, S. (2006). Núcleos de significação como instrumento para a apreensão da constituição dos sentidos. Psicologia Ciência e Profissão, 26(2), 222-245.

Amorim, M. A. \& Salej, A. P. (2016). O conservadorismo saiu do armário!: a luta contra a ideologia de gênero do Movimento Escola Sem Partido. Ártemis, 22(1), 32-42. doi: 10.15668/1807$8214 /$ artemis

Avila, A. H, Toneli, M. J. F., \& Andaló, C. S. A. (2013). Posturas docentes: algumas (im)possibilidades $e$ instabilidades da educação sexual que não fala de sexo como prazer e direito. In M. C. S. Lago, M. J. F. Toneli, \& M. Souza, Sexualidade, gênero, diversidades (pp. 252-265). São Paulo: Casa do Psicólogo.

Bock, A. M. B, Gonçalves, M. G. \& Furtado, O. (2002). Psicologia Sócio-Histórica: uma perspectiva crítica em Psicologia. São Paulo: Cortez.

Butler, J. (2003). Problemas de gênero: feminismo e subversão da identidade (R. Aguiar, Trad.). Rio de Janeiro: Civilização Brasileira.

Cohen, S. (1972). Folk Devils and Moral Panics: The Creation of Mods and Rockers. London: MacGibbon \& Kee.

Cornejo-Valle, M. \& Pichardo, J. I. (2017). La "ideología de género" frente a los derechos sexuales y reproductivos. El escenario español. Cadernos Pagu, (50), 175009 . doi: 10.1590/18094449201700500009

Costa, A. B. (2013). Síntese de políticas LGBTTs nacionais, estaduais e locais. In H. C. Nardi, R. S. Silveira \& P. S. Machado, Diversidade sexual, relações de gênero e políticas públicas (pp. 197-204). Porto Alegre: Sulina.

Cunha, F. M. (2016). O túnel, o Frota, a ideologia de gênero. Ponto Urbe: Revista do núcleo de antropologia urbana da USP, (18), 114. doi: $10.4000 /$ pontourbe. 3137

Facchini, R. \& Parreiras, C. (2017, Junho 28). "I deologia de gênero": índice de um fenômeno político transnacional. SciELO em Perspectiva: Humanas. Retirado de http://humanas. blog. scielo. org/blog/2017/06/28/ideologia-degenero-indice-de-um-fenomeno-politico-transnacional/ 
Ferreira, I. L. et al. (2015). Requerimento de informação no 565/2015. Brasília: Câmara dos Deputados. Retirado de http: //www.camara.gov.br/sileg/integras/1337320.pdf

Foucault. M. (1988). História da Sexualidade I: a vontade de saber. Rio de Janeiro: Graal.

González Rey, F. L. (2002). Pesquisa qualitativa em psicologia: caminhos e desafios. São Paulo: Pioneira/Thomson Learning.

Junqueira, R. D. (2009). Educação e Homofobia: o reconhecimento da diversidade sexual para além do multiculturalismo liberal. In R. D. Junqueira (Org.), Diversidade Sexual na Educação: problematizações sobre a homofobia nas escolas (pp. 95-124). Brasília: Ministério da Educação, UNESCO.

Lucci, M. A. (2006). A Proposta de Vygotsky: A Psicologia Sócio Histórica. Revista de curriculum y formación del profesorado, 10, 01-10.

Madureira, A. F. A. \& Branco, Â. U. (2015). Gênero, sexualidade e diversidade na escola a partir da perspectiva de professores/as. Temas em Psicologia, 23(3), 577-591. doi: https://dx.doi.org/10.9788/TP2015.3-05

Melo, L., Freitas, F., Pedrosa, C., Brito, W. (2012). Para além de um kit escola sem homofobia: políticas públicas de educação para a população LGBT no Brasil. Bagoas: Revista de Estudos Gays, (7), 99- 122.

Neves, A. L. M. (2013). Significados atribuídos por professores a protagonismo em projetos de igualdade de direitos voltados à diversidade sexual (Dissertação de Mestrado). Universidade Federal do Amazonas, Manaus.

Neves, A. L. M., Sadala, K. Y., Silva, I. R., Teixeira, E., Ferreira, D. S. $\&$ Silva, F. A. (2015). Representações sociais de professores sobre diversidade sexual em uma escola paraense. Psicologia Escolar e Educacional, 19(2), 261-270. doi: https: //dx.doi.org/10.1590/2175-3539/2015/0192831

Neves, A. L. M. \& Silva, I. R. (2015). Diversidade sexual e protagonismo de professores: uma análise sócio-histórica dos significados. São Paulo: Martinari.

Neves, A. L. M. \& Silva, I. R. (2017). Significações do protagonismo dos/as professores/as na igualdade de direitos à população Lésbicas, Gays, Bissexuais, Travestis e Transexuais (LGBT). Interthesis, 14(2), 92-112. doi: 10.5007/18071384.2017v14n2p93

Prado. M. A. M., Torres, M. A., Machado, F. V. \& Costa, F. A. (2009). A construção de silenciamentos: reflexões sobre a vez e a voz de minorias sociais na sociedade contemporânea. In C. Mayorga, E. F. Rasera, \& M. S. Pereira, Psicologia Social: sobre desigualdades e enfrentamentos (pp. 31-49). Curitiba: Juruá. 
Rosa, E. \& Andriani, A. (2008). Psicologia Sócio-histórica: uma tentativa de sistematização epistemológica e metodológica. In E. M. P. Kahhale, A diversidade da psicologia: uma construção teórica (pp. 259-288). São Paulo: Cortez.

Silva, A. K. L. S. (2013). Diversidade sexual e de gênero: a construção do sujeito social. Revista do NUFEN, 5(1), 12-25.

Silva, I. R. \& Maciel, D. M. A. (2006). A atuação do psicólogo na educação: configuração progressiva de um espaço de atuação profissional. Amazônida, 11, 54-76.

Vigotski, L. (2001). Pensamento e Linguagem. São Paulo: Martins Fontes.

\author{
Endereço para correspondência \\ André Luiz Machado das Neves \\ Universidade do Estado do Amazonas - UEA \\ Av. Carvalho Leal, 1777, Cachoeirinha, CEP 69065-001, Manaus - AM, Brasil \\ Endereço eletrônico: andre_machadostm@hotmail.com \\ I olete Ribeiro da Silva \\ Universidade Federal do Amazonas - UFAM \\ Campus Universitário Coroado I \\ Av. Gen. Rodrigo Octávio J ordão Ramos, 6.200, Setor Sul, Bloco X, CEP 69080-900, \\ Manaus - AM, Brasil \\ Endereço eletrônico: iolete.silva@gmail.com
}

Recebido em: 30/04/2015

Reformulado em: 15/09/2017

Aceito em: 15/09/2017

\title{
Notas
}

* Mestre em Psicologia pela Universidade Federal do Amazonas - UFAM e Doutorando em Saúde Coletiva pela Universidade do Estado do Rio de Janeiro UERJ, Professor da Escola Superior de ciências da Saude - ESA da Universidade do Estado do Amazonas.

** Mestre e Doutora em Psicologia pela Universidade de Brasília, Professora Associada da Universidade Federal do Amazonas (UFAM) e do Programa de PósGraduação em Psicologia/UFAM e Programa de Pós-Graduação em Educação/UFAM. 1 Metáfora baseada no movimento de "militares cristãos" ou "soldados de cristo", que visavam doutrinar outros povos que não professavam o cristianismo.

2 Ver em Cornejo-Valle \& Pichardo (2017).

30 protagonismo se dá no processo de superar as adversidades, resistir às pressões, modificar o seu entorno, adaptar-se constantemente às exigências do mundo atual (Silva, 2010).

4 Intervenções, ações de enfrentamento às adversidades, resistência às pressões e/ou a qualquer tipo de exclusão social. Exemplo: palestras, articulação de temas sobre direitos humanos em ambientes institucionais e programas específicos que promovam a discussão de igualdade de direitos pensando as diferenças na saúde, na educação e assistência social (Neves \& Silva, 2015).

Este artigo de revista Estudos e Pesquisas em Psicologia é licenciado sob uma Licença Creative Commons Atribuição-Não Comercial 3.0 Não Adaptada. 